\title{
The Localization of General Education of Universities in Taiwan
}

\author{
Max M -Z. Yan, Kao Liu \\ Institute of Vocational Instructors of Tongji University, Shanghai, China
}

\begin{abstract}
Yale University as a representative of the practice for General Education has been about 200 years since 19 century, and then the idea of General Education has also been practiced in higher education of some countries and areas in Europe and East Asia. This paper focuses on observing the concept of General Education, analyzes the localization practice of universities in Taiwan, gets some important enlightenment. It has to focus on the cultivation of independent personality in theory; realize the innovation of national culture in localization; emphasize the local cultivation of teachers; build special department to make sure the achievement of general education.
\end{abstract}

Keywords-Universities in Taiwan, General Education, Localization, Personality Perfection, Culture Innovation

\section{台湾高校通识教育本土化建构及启示}

\author{
颜明忠 刘考 \\ 同济大学职业技术教育学院，上海，中国
}

\begin{abstract}
摘 要 自 19 世纪以来, 以耶鲁大学为代表的通识教育实践至今已有近 200 年的历史, 其后通识教育理念在欧洲和东亚一些国 家和地区的高等教育中亦有实践。本文着重于考察通识教育的内涵, 分析台湾高校通识教育本土化的实践, 给我们以重要启示。在理 念上必须着眼于独立人格的培养; 在本土化实践中实现民族文化创新; 注重本土化师资的培养; 建立不同特色的专门部门保障通识教 育运行。
\end{abstract}

关键词 台湾高校, 通识教育, 本土化, 完善人格, 文化创新

通识教育作为高等教育领域一种思想, 从总体上来说 经历了很长的发展时期, 纵观西方、台湾、香港和大陆的 通识教育发展历程, 西方发展历史悠久, 已经形成了符合 本土文化的理念; 我国大陆和香港通识教育思想起步在 20 世纪 90 年代左右, 时间较晚, 还没有形成其完整的大学理 念; 但台湾经历了从 50 年代左右借鉴美国等西方国家的通 识教育思想到开始进行独立探索, 融入中国传统文化, 实 现高校通识教育本土化建构, 研究台湾高校通识教育本土 化过程有利于丰富高等教育思想, 同 时为通识教育发展提 供一种可供借鉴的新方向探讨。

\section{1. 通识教育及其意义}

\section{1 通识教育概念的界定}

通识教育是一个复杂的概念, 从字面意义上来看, 它 与“专业教育”或“职业教育”相对。在大学或高等教育实践
的阶段划分上看, 她表现为在大学低学年阶段所实施的“专 业” (职业) 教育的基础知识, 或人类一般社会历史文化知 识的教学, 是一个受过高等教育的人日后做人做事所需的 “基础性”、“通识性”教育素养。目前, 高等教育学界对于 何谓“通识教育”仍然是众说纷纭, 莫衷一是。由于通识教 育概念的不确定性, 一定程度上造成了人们对其认识的混 乱。[1]我国大陆学者李曼丽认为, 通识教育有广义和狭义 之分。广义是指称大学的整个办学思想或观念; 狭义是指 称不直接为学生将来的职业活动做准备的那部分教育。[2] 我国台湾学者黄俊杰教授则认为, 通识教育是一种完成人 之觉醒的教育。

根据前述分析, 我们认为, 在理念层面上通识教育是 广义的, 即通识教育的最终目标在于促进学生的全面健康 发展, 是一种大学教育观, 居于办学思想的层次; 在实践 层面上通识教育的载体是狭义的, 即主要是指通识教育的 
目的是为了促进个体人格的自我完善, 同时开展通识教育 的机构是明确的, 通识教育课程设置也是具体的。

\section{2. 台湾地区高校通识教育的本土化探索}

2.1 台湾地区高校通识教育的发展历程

台湾通识教育探索开始的时间比较早, 一般认为, 20 世纪 50 年代是起始阶段。台湾通识教育的发展经历了萌芽 (1950-1984 年)、起步（1984-1994 年）与发展（1994-至 今）三个历史阶段。[3]

（1）萌芽阶段（1950-1984 年）

1956 年美国基督教会创办的东海大学申报开设“宏通 教育”, 后被批准于同年开办了 “通才教育”, 并聘请美国专 家来台指导。[4]在此期间, 台湾东海大学开始致力于学生 各方面的发展, 也培育了不少人才。但这一时期台湾通识 教育还未成熟, 仍然处于探索阶段。

（2）起步阶段（1984-1994 年）

1984 年台湾教育行政部门颁布由 1983 年李亦园等人 起草的《大学通识教育及共同科目之综合建议》报告书。 要求所有高校在文学与艺术、历史与文化、社会与哲学、 数学与逻辑、物理科学、生命科学、应用科学与技术等 7 大学术范围内开设各种选修科目, 办理通识教育 4 至 6 学 分的课程。[5]这标志着台湾通识教育的普遍开展。与此同 时, 通识教育的研讨与交流活动也非常频繁, 并于 1984 年 4 月成立了台湾通识教育学会, 创办了《通识教育季刊》。 [6]这些举措都有力的推动了台湾通识教育的开展。但这一 时期的通识教育实践也存在着很多问题, 如准备不足、理 解不够、关注缺乏等, 通识教育理念仍然未得到应有的重 视。

\section{(3) 发展阶段（1994一至今）}

1995 年台湾“司法院大法官会议”正式宣告“部定共同 必修科目”因违宪而被废除。[7]这时各个大学也开始重新探 索通识教育该如何发展的问题。这一时期通常被认为是台 湾通识教育的大力发展时期, 台湾通识教育实践得以大面 积展开, 如通识教育开始被列入 “教育部”的正式工作议程, 开始开展通识教育的教育评估鉴定工作。1997 年, 台湾通 识教育学会受台湾当局“教育部高教司委托”, 开始设计大 学院校通识教育评鉴实施计划, 并于 1999 年完成 58 所高 校的通识教育评鉴工作。[8]但最重要的阶段性特征是台湾 地区已经开始通识教育的本土化建构过程。

台湾地区的通识教育发展至今, 相比于大陆和香港, 冊庸置疑取得了更为迅速的进步和发展。到目前为止, 台 湾各高校现都基本开设有通识教育的课程, 并成立有“中华
民国通识教育学会”等学术研究机构, 同时开办了《通识教 育季刊》等相关学术期刊。这是值得祖国大陆和香港等地 区高校学习借鉴的重要经验。

\section{2 台湾地区高校通识教育的实践}

\subsection{1 通识教育课程的设置}

课程是实施某一教育思想的最直接、最有效的方式或 载体, 通识教育思想的贯彻与否很大程度上取决于其课程 设置是否普及和完善。台湾地区在发展通识教育的过程中, 其最大的特色在于注重中华文明价值观的传承, 下面举出 几例来作简要介绍。

\section{(1)宜兰大学的“周易与人生”课程}

宜兰大学通识教育中心开设这门“周易与人生”的价值 观课程, 旨在以此为机会讲授易经展现的宇宙人生现象和 道理, 其教师来源与人文与社会科学教育中心。同时所选 用的教材也是中国古代名著, 如朱喜的《周易本义》等。

\section{(2) 台湾大学的“老子与道德经新译”课程}

“老子道德经新译”也是台湾大学一门重要的通识教育 课程。开设该课程是以中国古代道家思想为源, 向学生传 授中华文明的价值观。其中老子《道德经》第一章原文为“道 可道, 非可道, 名常名, 非常名。”任课教师在给学生原文 后又给出通俗的“宇宙间万事万物的本原, 都是可以说出来 的, 但它不是永恒不变的本原; 各种事物的名称都能够称 呼它 (都能够叫出名称来), 但它不是永远不变的”这一解 释。用这种方式使学生们更为了解和理解中华文化。[9]

(3) 台湾中原大学“中国语文”课程

台湾中原大学开设这门课程, 占所修通识教育课程学 分的 6 个学分, 其主要教师来源于台湾和大陆精通中国文 化、历史的学者, 以传承中华传统价值为目的, 旨在向学 生介绍中国历史、文学等价值观念。

\subsection{2 通识教育专门机构}

台湾高校的通识教育在发展的初期同样向美国学习, 如建立“通识教育委员会”等专门机构来保障其教育理念的 实施。但通过分析不难发现, 台湾在建立专门机构的基础 上也根据其实际情况进行了一些本土化的探索。目前, 其 主要的领导通识教育实施的机构有以下三种方式: 一是学 校设立了整体的通识教育中心, 负责全部的师资人员、课 程安排、讲座等的通识教育实践方式, 如国立清华大学; 二是在条件不具备的情况下, 成立学校共同教育委员会的 组织机构, 但具体的通识教育课程设置仍然由各学系承担, 开设课程等, 如台湾大学; 三是中间类型, 即只有通识教 育的管理机构, 但并无专任教师。[10]但不论哪种形式, 都 
是在台湾各高校根据本校实际情况, 积极探索通识教育的 实践模式而建立起来的, 充分体现了其 “校本化” 的通识教 育理念。

\section{3. 启示}

\section{1 通识教育理念有助于完整人格的培养}

台湾通识教育也可以被称为“全人教育”, 台湾“大学教 育改革促进委员会”所著《台湾高等教育白皮书》认为: “通 识教育的目的乃在于透过适当之课程的设计, 使学生对人、 社会、自然的诸现象有一通盘、初步之知识上的认识, 以 助于形塑有追求真善美之理想的能力和意愿, 也有助于培 养自我反省能力之独立人格, 同时, 更重要的是, 协助学 生对其所扮演的社会角色有更为宽广的体认”[11]。即通识 教育目的的实现注重通过培养学生对于社会、自然和人等 方面的全面认识来培养学生独立的人格。

如前所述, 台湾高校通识教育的内容包括人文素养、 社会关怀和现代科学技术等方面。人文素养有利于培养学 生对于文学艺术的敏感, 形成正确的伦理道德; 社会关怀 则是引导学生关注社会事务、培养学生的社会意识; 而其 他方面如自然关怀、科技等都是促进个人人格完善不可或 缺的组成部分。教育的终极目的是人格完善, 诚如德国哲 学家费希特所说: “教育必须培育人的自我决定能力, 不是 首先要去传授知识和技能, 而是要去 “唤醒, 学生的力量”。

\section{[12]}

3.2 大陆实现通识教育课程本土化过程有助于进行文化创 新

通识教育课程作为教育理念的重要实践环节, 在实施 过程中内容是否完善、措施是否得力, 都对教育效果产生 影响。从上世纪 80 年代起开始, 台湾高校借鉴美国通识教 育课程设置经验的基础上, 如今已经形成了别具本土化特 色的课程体系。主要表现在台湾学者不仅仅是借鉴具有西 方文化特色的通识教育课程, 更是开始实现东西文化撞击 交融中的再创新。

中华文明是几千年历史的沉淀, 在当下越来越浮躁的 社会, 人们只是醉心于追求功名利禄, 却忘记了个人修养, 回首几千年前中国的古老文化, 儒家的“中庸”、道家的“无 为”、墨家的“兼爱”“非攻”, 开始给我们以更多的启迪。传 统文化的熏陶能使我们保持自己心灵的平静, 做一个真正 具有完善人格的主体。

如前所述, 列举了台湾大学、台湾中原大学等几所高 校的通识教育课程设置的情况, 可以看到台湾高校在设置 通识教育课程的过程中始终强调中华传统文化的传承和延
续。台北科技大学校长李祖添博士认为, 中国传统文化艺 术与自然科学技术的结合能使学生的心灵通透, 有利于创 新能力的培养。[13]

\section{3 注重通识教育本土化师资的培训}

教师的师德、学识、人格魅力对教育的全过程起决定 性作用。[14]台湾在通识教育发展过程中一直注重师资的培 养工作。它要求教师既要有较高的专业学术水平, 又要有 较为宽广的知识面, 同时还要具有运用不同理论分析和解 决问题的意识、方法和能力, 否则是不可能有高质量的通 识教育质量的。[15]在 80 年代, 台湾高校刚开始实施通识 教育的阶段, 其教师水平不高, 知识面窄, 教授自然科学 的教师缺乏人文社会科学知识素养。

这一现象, 曾一度引起台湾教育当局的高度重视。为 解决通识教育师资问题做了如下几方面的工作。首先, 应 聘请学识水平高、知识面广、了解中国传统文化的学者和 教授, 作为担任通识教育课程师资的培训教师; 其次, 作 为一名传授中华文化的教师也应该具有良好的语言表达能 力, 以便能把晦涩难懂的中国古文以白话文的形式为学生 解释其意义; 再次, 通识教育教师也应该给学生推荐相关 的具有丰富传统文化内涵的书籍, 如可以推荐《资治通鉴》 《红楼梦》等具有代表性的书目。

台湾“通识教育学会”也重视各个高校的通识教育师资 培养工作。如各大学经常举办关于 “教师发展与通识教育” 的研讨会, 聘请国外知名专家学者开办讲座, 开展教师教 学观摩活动等, 后来台湾各大学也相继设立了“教师教育培 训中心”等机构。为鼓励优秀教师投入通识教育, 台湾当局 “教育部”于 2007 年设立了“杰出通识教育教师奖”, [16]通 过建立荣誉制度或激励机制, 鼓励广大教师积极投身于通 识教育事业。

\section{4 建立不同特色的专门机构, 保障通识教育运行}

台湾高校通识教育的最重要的特色之一, 即是在开展 通识教育的几十年里已经形成了极具特色的一套通识教育 运行体系和机制。自 20 世纪 90 年代起, 台湾各高校在学 习借鉴美国通识教育机构的基础上，也根据实际情况成立 了适合于本校的专门机构, 如国立清华大学成立的“通识教 育中心”, 这是值得大陆借鉴和学习的方面。

比较而言, 目前我国大陆高校虽然意识到了通识教育 的重要性, 但在实践层面则往往缺乏行动, 除了少数研究 型大学设立了专门实施通识教育的学院, 如复旦大学的“复 旦学院”, 中山大学的“南方学院”通识教育中心, 而其他大 学尚未设立专门的通识教育运行机构, 其通识教育的任务 多由教务处负责管理。而教务处由于教学事务繁多, 往往 
没有精力放在通识教育上面。因此, 大陆高校更需要设立 专门的通识教育机构来统整通识教育的实施。

\section{参考文献(References)}

[1] Xiaojie Fan, Statistical Analysis of Research Papers on General Education in China, Higher Education Research Institute, vol 2, 2007.

[2] Manli Li and Yongquan Wang, Discussion on "General Education" Concept Connotation, Research on Education Tsinghua University, vol 1, 1991.

[3] [9][10] Lili Guan, the Comparation between General Education in Taiwan and Quality Education in Mainland, Educational Theory Research, 2010.

[4] Zengjun Feng, The Analysis of General Education in Taiwan in China, Comparative Education Research, vol 12, 2003.

[5] [7][8][16] Deqi Zhang, The Curriculum Development and Characteristics of General Education of Universities in Taiwan Hebei Normal University Journal (Education Science Edition), vol 9, 2009.
[6] Haishao Pang, The General Education: The Comparation between Taiwan and Mainland, Higher Education Research in China, vol 6, 2007.

[11] Ming Hong, The General Education in Taiwan, Research in Higher Education of Engineering, vol 2, 1997.

[12] Junyao Zhao, Useful Insights of Traditional Cultural Education of Universities in Taiwan, Fujian Socialist College Journal, vol 5, 2012

[13] Jian Chang, Strenghten Quality Education and Accumulate University Culture, Chongqing Science and Technology Journal (Social Science Edition), 2007.

[14] Huiming Feng and Mingdong Huang, Implementation Strategy and its Implications of General Education in Universities in Taiwan, Wuhan University Journal (Humanity Edition), vol 9, 2006.

[15]Xiaohui Jia and Lixin Yang, the Comparation between Quality Education in Mainland and General Education in Taiwan, Adult Education, vol 5, 2011. 